\title{
Prevalence of Disability and Associated Factors among Registered Leprosy Patients in All Africa Tb and Leprosy Rehabilitation and Training Centre (ALERT), Addis Ababa, Ethiopia
}

\author{
Tigist Shumet $^{1,2}$, Meaza Demissie ${ }^{1}$, Yonas Bekele ${ }^{3,4}$
}

\begin{abstract}
BACKGROUND: Delay in leprosy diagnosis and treatment causes disabilities due to nerve damage, immunological reactions and bacillary infiltration. Leprosy disability leads not only to physical dysfunction and activity limitation but also disrupts social interaction of affected individuals by creating stigma and discrimination. This study was aimed at assessing leprosy disability status in patients registered at All African TB and Leprosy Rehabilitation and Training Centre.
\end{abstract}

METHODS: Medical records of leprosy patients registered from September 11, 2010 to September 10, 2013 G.C were reviewed. Prevalence of disability calculated, bivariate and multiple logistic regressions were used to determine crude and adjusted odds ratios with $95 \%$ confidence interval.

RESULTS: The overall prevalence of disability was found to be $65.9 \%$ from all categories of patients (40.2\% Grade I and 25.7\% Grade II). The Prevalence among the new category was $62.8 \%$ (39.1\% Grade 1 and $23.7 \%$ Grade 2). Those ageed above 30 years, with duration of symptoms 6-12 months and above 24 months, with sensory loss, nerve damage and reversal reaction were more likely to develop disability. CONCLUSION: In this study the prevalence of disability, both Grade I and II, is very high. Disability was associated with age, duration of symptom, sensory loss, signs of nerve damage and reversal reaction. These risk factors indicate the existence of delay in diagnosis and treatment of leprosy cases. Therefore, the national leprosy control program should investigate leprosy case detection and diagnosis system in the country and work on improving early case detection and prevention of disability.

KEYWORDS: Leprosy, leprosy disability, Ethiopia

DOI:http://dx.doi.org/10.4314/ejhs.v25i4.4

\section{INTRODUCTION}

Leprosy is a chronic disease caused by Mycobacterium leprae. The causative agent affects peripheral nerves and causes damage by binding with Schwann cells which are important for conducting nerve impulses $(1,2)$. The interaction of $M$. leprae with Schwann cells causes irreversible loss of peripheral nerve tissue followed by disabilities (3). In some case, nerve damage occurs without skin lesions which make diagnosis difficult leading to further damage.
Leprosy related disability is preventable if diagnosed early; but many cases are diagnosed late with disability of significant physical impairment. The damage is not limited to the physical inability but also creates a negative image leading to discrimination and social stigma against the affected individuals and their families (4).

The burden of leprosy can be measured in terms of the occurrence of reported new cases, or of the number of cases registered for treatment, or the number of cases with disabilities. In Ethiopia, a total of 4374 (4028 MB and $346 \mathrm{~PB}$ ) new

\footnotetext{
${ }^{1}$ Addis Continental Institute of Public Health, Addis Ababa, Ethiopia

${ }^{2}$ Addis Ababa University Faculty of Medicine, Addis Ababa, Ethiopia

${ }^{3}$ Armauer Hansen Research Institute, Addis Ababa, Ethiopia

${ }^{4}$ Department of Microbiology, Tumor and Cell Biology, Karolinska Institutet, Stockholm, Sweden

Corresponding Author: Meaza Demissie, Email: meazademissie@gmail.com
} 
leprosy cases was reported in 2013 which is lower than the report in the previous year. Among these, 4374, 466(10.65\%) were children and $361(8.25 \%)$ of new cases of leprosy had disability grade II (5).

The major risk factors known for leprosy disability and physical deformity are delay in diagnosis, and delay in provision of proper care for the disease. The other known risk factors are multiple nerve enlargements, the type of leprosy(pauci or multi bacillary), smear result and age (6-8).

The World Health Organization's 2011-2015 global strategy for leprosy control focuses on reducing the rate of new leprosy cases with grade II disabilities per 100,000 people by at least $35 \%$ at the end of 2015 taking 2010's occurrence as reference (9). To achieve this goal, the measures to be taken are to detect and treat the disease early before nerve damages occur. Early diagnosis of grade I disability is also an important measure to prevent development of disability to the second stage which has serious physical and psychological damage to the patient. This study aimed at assessing the prevalence of disability and associated factors among registered leprosy patients in All African TB and Leprosy Rehabilitation and Training Centre, Addis Ababa.

\section{METHODS}

Study setting: The study was conducted in All African TB and Leprosy Rehabilitation and Training Center (ALERT) in Addis Ababa, the capital city of Ethiopia. The center currently serves as a general teaching hospital, has 240 beds and consists of dermatology, ophthalmology, surgery and orthopedic departments. It also has an orthopedic workshop and a rehabilitation program. The leprosy treatment unit on the average sees around 470 patients annually. It provides service to patients coming from all regions of the country.

Study design: A cross sectional retrospective record review was used to gather the data. Medical records of leprosy patients registered from September 11, 2010 to September 10, 2013 were reviewed.

Sample size and sampling procedure: Sample size was calculated using single population proportion formula with the following assumptions: marginal error (d) of $4 \%$ with $95 \%$ confidence interval and prevalence of disability $31 \%$. The calculated sample size was 513. Systematic sampling was used to select data from registers. First, the interval (k value) was calculate using the formula ( $\mathrm{K}=1417 / 513)$. Then, starting point was selected by using simple random sampling method from the first kth value and data were reviewed for every 3rd patient.

Data Collection Procedure: Data were collected by 2 trained nurses, who were working in leprosy treatment unit. Predesigned data abstraction form was used for data collection.

Variables: The dependent variable was disability (no disability or grade I or II disability). The independent variables were Age, Sex, Address, Type of Leprosy (MB,PB), Number of Skin Lesion, Smear Result, Category of Treatment (New, Relapse, Defaulter and Others), Duration of Symptom, Thickened Nerve, Reversal Reaction, Erythema Nodosum Leprosum (ENL), Care Given to the Patient while on MDT, Initiation of Steroid Treatment and the Chief Complaints.

\section{Operational Definitions}

DG 0 - no disability caused by leprosy in eyes, hands and feet

DG 1 - Eye problem caused by leprosy, but vision is not severely affected (equals $6 / 60$ or better; fingers can be counted at six meters apart); loss of sensibility in hands or feet.

DG 2 - Eyes: lagophthalmos and/or ectropion; trichiasis; visual impairment (fingers not counted at $6 \mathrm{~m}$ ) Hands and feet: with visible damage i.e. claw hands, foot drop, reabsorption of fingers or toes, wounds) $(10,11)$.

Pauci-bacillary- five or fewer lesions with no bacteria detected in the skin smear (sample taken from the area)

Multi-bacillary- More than five lesions or a bacterium is detected in the skin smear, or both.

New case- A patient with MB or PB leprosy who has never had treatment for leprosy before.

Relapse: a patient declared "treatment completed" after a course of MDT but who reports back to the $\mathrm{HF}$ and found to have active leprosy

Return after default- an $\mathrm{MB}$ or $\mathrm{PB}$ who returns for treatment after having missed more than 3 months "dose of MDT (both cumulative and consecutively)"

Transfer in- a patient received from another HF to continue treatment 
Others- any leprosy patient requiring chemotherapy who does not fit in any of the above mentioned categories, including patient with relapse after treatment with dapsone mono therapy in the past (12)

Data management and analysis: The collected data were checked by the principal investigator (PI) on daily basis for any incompleteness and/or inconsistency. When any incompleteness and/or inconsistency appeared, corrections were made by re-checking them back against the records. Data entry was done using EPI info. Then, the data were exported to SPSS statistical software for analysis.

Frequencies were used to calculate the prevalence of disability; bivariate and multiple logistic regression were done to calculate the crude and adjusted odds ratios with the 95\% confidence interval.

Ethics: Ethical approval was obtained from ALERT hospital IRB. Patients' names were not recorded and data were accessed only by the investigators.

\section{RESULTS}

Socio-demographic characteristics: A total of 513 complete records were reviewed. Patients who visited the hospital for 3 years (Sep 11, 2010 to Sep 10, 2013) were included. Out of those involved in this study, $98.1 \%$ reported by themselves; of these, 328(63.9\%) were male and $185(36.1 \%)$ were females patients. Twenty-five (4.9\%) of the leprosy patients were aged less than or equal to 14 years. Two hundred and twenty-five $(43.9 \%)$ were aged 15 to 30 years. One hundred and seventy-two $(33.5 \%)$ were in the age group of 30-50. The remaining $91(17.7 \%)$ were above 50 years old (Table 1). The majority of the patients came from outside Addis Ababa: 36. 6\% from Oromia Region, 32.4\% from Amhara Region and only $16 \%$ were from Addis Ababa (Table 1).

Clinical characteristics of the patients: Three hundred and seventy-nine (73.9\%) of the patients were newly diagnosed cases of leprosy, 11(2.1\%) were returnees after default, 35(6.8\%) were relapse and the remaining $88(17.2 \%)$ were in other categories (Table 1). Almost all of the patients were multi-bacillary (MB) leprosy cases, $509 / 513(99.2 \%)$. Loss of sensation was reported in $305(59.5 \%), 294(57.3 \%)$ of the leprosy patients were started on steroid treatment. Among the patients who had reversal reaction, $89.8 \%$ were started on steroid treatment. In addition, there were 80 leprosy patients from the total who had Erythema Nodosum Leprosum (ENL) who were on steroid treatment (Table 1). Prevalence of disability and factors associated with aisability From the total of 513 patients, 338(65.9\%) had disability. Two hundred and six $(40.2 \%)$ had disability grade I and 132 (25.7\%) had grade II disability (Figure 1). Prevalence among the new category was $62.8 \%$ (39.1\% Grade I and $23.7 \%$ Grade II).

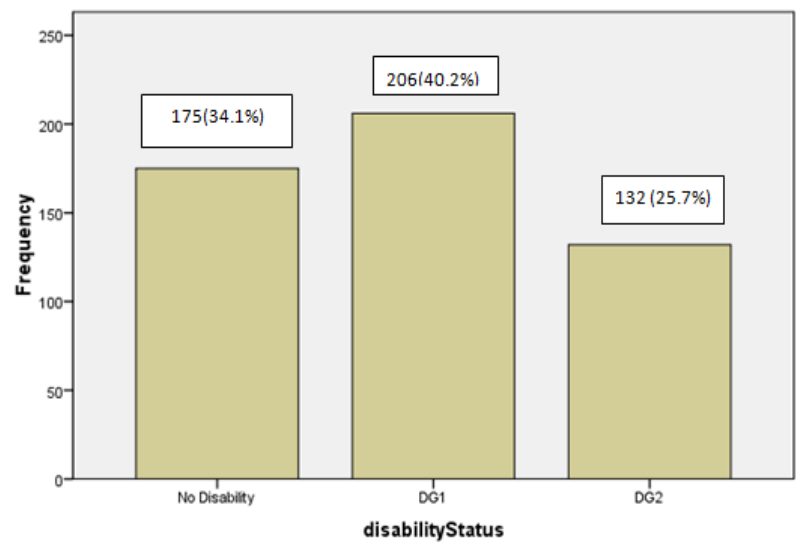

Figure 1: Disability status of leprosy patients registered from September 11, 2010 to September 10, 2013, ALERT Hospital, Addis Ababa, Ethiopia

DG1: Disability grade I

DG2: Disability grade II

Factors Associated to Disability 
Table 1: Socio-demographic and clinical characteristics of leprosy patients registered in ALERT Hospital from September 11, 2010 to September 10, 2013, Addis Ababa, Ethiopia

\begin{tabular}{|c|c|c|c|}
\hline Variables & Characteristics & Frequency & Percent \\
\hline \multirow[t]{2}{*}{ Sex } & Male & 328 & 63.9 \\
\hline & Female & 185 & 36.1 \\
\hline \multirow[t]{4}{*}{ Age } & $\leq 14$ & 25 & 4.9 \\
\hline & $\geq 15$ to 30 & 225 & 43.9 \\
\hline & $\geq 31$ to 50 & 172 & 33.5 \\
\hline & $\geq 51$ & 91 & 17.7 \\
\hline \multirow[t]{5}{*}{ Address(Region) } & Addis Ababa & 92 & 17.9 \\
\hline & Amhara region & 166 & 32.4 \\
\hline & Oromiya region & 188 & 36.6 \\
\hline & SNNP region & 49 & 9.6 \\
\hline & Others & 18 & 3.5 \\
\hline \multirow{2}{*}{ Method of case finding } & Voluntary (passive) & 503 & 98.1 \\
\hline & Contact Tracing & 10 & 1.9 \\
\hline \multirow[t]{4}{*}{ Duration of symptom } & $\leq 6$ Months & 138 & 26.9 \\
\hline & $\overline{6}$ to 12 months & 150 & 29.2 \\
\hline & 12 to 24 Months & 81 & 15.8 \\
\hline & $>24$ Months & 144 & 28.1 \\
\hline \multirow[t]{2}{*}{ Type of leprosy } & Multi Bacillary & 509 & 99.2 \\
\hline & Pauci Bacillary & 4 & 0.8 \\
\hline \multirow[t]{4}{*}{ Treatment category } & New & 379 & 73.9 \\
\hline & Defaulter & 11 & 2.1 \\
\hline & Relapse & 35 & 6.8 \\
\hline & Others & 88 & 17.2 \\
\hline \multirow[t]{3}{*}{ Number of skin lesion } & No skin lesion & 128 & 25 \\
\hline & 1 to 5 & 25 & 4.9 \\
\hline & $\geq 6$ & 360 & 70.2 \\
\hline \multirow{2}{*}{ Sensory loss } & Present & 305 & 59.5 \\
\hline & Absent & 208 & 40.5 \\
\hline \multirow[t]{3}{*}{ Smear result } & Not Done & 14 & 2.7 \\
\hline & Smear Positive & 213 & 41.5 \\
\hline & Negative & 286 & 55.8 \\
\hline \multirow[t]{2}{*}{ Thickened nerve } & Yes & 316 & 61.6 \\
\hline & No & 197 & 38.4 \\
\hline \multirow[t]{2}{*}{ Steroid started } & Yes & 294 & 57.3 \\
\hline & No & 219 & 42.7 \\
\hline \multirow[t]{2}{*}{ Reversal Reaction(RR) } & Present & 147 & 28.7 \\
\hline & Absent & 366 & 71.3 \\
\hline \multirow{3}{*}{ ENL } & Present & 93 & 18.1 \\
\hline & Absent & 420 & 81.9 \\
\hline & Total & 513 & 100 \\
\hline
\end{tabular}


Table 2 gives details on factors associated with disability (either grade I or grade II). All the variables which are associated with disability in the bivariate analysis, except treatment category, maintained their association in the multiple logistic regression analysis. Age greater than 30: those in age group 30-50 years AOR $3.98 \mathrm{CI}(1.36-$ $11.65)$, $\mathrm{p}$ value 0.011 and those $50+$ years AOR 6.61 CI (2.04-21.33), p 0.002. Patients with duration of symptom 6 to 12 months and those greater than 24 months were also more likely to develop disability, AOR $2.13 \mathrm{CI}(1.14-3.96)$, p 0.017 and $>24$ months AOR 2.491 CI(1.31-4.72),p 0.005 . Those who presented with sensory loss were also more likely to have disability, AOR 1.72 CI (1.07-2.77), p 0.036. Sign of nerve damage and reversal reaction were also associated with higher disability rate, AOR and 95\% CI: $13.10 \mathrm{CI}$ (8.0721.25), p 0.000, $1.85 \mathrm{CI}(1.03-3.33), \mathrm{p}$ 0.038, respectively.

\section{DISCUSSION}

This study revealed that $65.9 \%$ of the leprosy patients studied had disability Grade I or II. Among those with disability, $40.2 \%$ had grade I and $25.7 \%$ had grade II disabilities. Age, duration of symptoms, sensory loss and nerve damage and reversal reaction are the factors found to be associated with disability.

The prevalence of disability in this study is very high as more than half of the patients presented with one kind of disability. This high prevalence of disability indicates the existence of problems in terms of early case finding and treatment. If patients had chance of being diagnosed early, they could have been cured from the disease before any of the complications appeared. Most of the patents in this study were from outside Addis Ababa. This could be because of misdiagnosis of patients in the peripheral health facilities, or patients may not have any knowledge to seek health care at early stage; by the time they develop disability they usually prefer to go far from their residence to seek medical help as they do not want to be recognized in their communities because of the stigma related with the disease.

Nearly $5 \%$ of the patients were aged less than 14 showing that transmission is still going on in the community. This high prevalnec in younger age group calls for more vigorous means of case detection like active search for cases especially in communities known to be leprosy endemic.

The prevalence of disability was found to be increasing as age increases. This also suggests that patients may have had symptoms for a long time without being diagnosed or treated. For patients in the age group greater or equal to 30 , disability was high; as people in this age group are engaged in physical work, they are vulnerable to different kinds of injuries. It is also possible that the older age groups may have had the disease for a long time without suspecting it to be leprosy; the only time they might have had suspicion would have been when they saw the damage in their body. Almost all of the factors found to be associated with disability are related to prolonged duration of symptoms or late diagnosis of patients. The longer the duration of symptoms the higher the likelihood of developing nerve damage and sensory loss, both of which subsequently lead to disability.

Among newly detected cases, the prevalence of grade II disability was $23.7 \%$. In African Region, the prevalence of grade II disability ranges from $2.1 \%$ in Comoros to $33.2 \%$ in Burknia Faso (4). In some countries of Asia, a higher rate of grades I and II disabilities have been reported $(48.7 \%$ grade I and $28.0 \%$ grade II in Indonesia). Report from the Federal Ministry of Health of Ethiopia shows relatively lower rate of grade I and II disabilities, 22\% and 9\%, respectively. These figures are different from what we have found $(39.1 \%$ and $23.7 \%$ ) and could be explained by the fact that the patients in our study were different as most of them came to this tertiary level hospital very late after the diseases had progressed. 
Table 2: Factors Associated with disability in leprosy patients registered in ALERT Hospital from September 11, 2010 to September 10, 2013, Addis Ababa, Ethiopia

\begin{tabular}{|c|c|c|c|c|c|c|}
\hline & \multirow[t]{2}{*}{ Characteristics } & \multirow{2}{*}{$\begin{array}{l}\text { Having } \\
\text { disability }\end{array}$} & \multirow{2}{*}{\begin{tabular}{|l} 
Not Having \\
disability
\end{tabular}} & \multirow[t]{2}{*}{ COR \& 95\%CI } & & \multirow[t]{2}{*}{ AOR } \\
\hline & & & & & Sig & \\
\hline \multirow[t]{4}{*}{ Age } & $\leq 14$ & $9(36 \%)$ & $16(64 \%)$ & 1.00 & & 1.00 \\
\hline & 15 to 30 & $131(58.2 \%)$ & $94(41.77 \%)$ & $2.47(1.05-5.84)$ & 0.177 & $2.04(0.72-5.79)$ \\
\hline & 31 to 50 & $124(71.1 \%)$ & $48(27.9 \%)$ & 4.59(1.90-11.09) & 0.011 & $3.98(1.36-11.64)$ \\
\hline & $\geq 51$ & $74(81.3 \%)$ & $17(18.7 \%)$ & $7.73(2.92-20.45)$ & 0.002 & $6.60(2.04-21.33)$ \\
\hline \multirow{4}{*}{$\begin{array}{l}\text { Duration } \\
\text { of symptom }\end{array}$} & $\leq 6$ Months & $60(43.5 \%)$ & $78(56.5 \%)$ & 1.00 & & 1.00 \\
\hline & 6 to 11 months & $50(33.3 \%)$ & $100(66.7 \%)$ & $1.53(0.95-2.48)$ & 0.017 & $2.13(1.14-3.96)$ \\
\hline & 12 to 24 Months & $27(33.3 \%)$ & $54(66.7 \%)$ & $1.53(0.86-2.72)$ & 0.231 & $1.55(0.75-3.18)$ \\
\hline & $>24$ Months & $38(26.4 \%)$ & $106(73.6 \%)$ & $2.14(1.30-3.54)$ & 0.005 & $2.49(1.31-4.72)$ \\
\hline \multirow{5}{*}{$\begin{array}{l}\text { Category of } \\
\text { Treatment }\end{array}$} & New & $238(62.8 \%)$ & $141(37.2 \%)$ & $0.46(0.26-0.80)$ & & $0.51(0.25-1.04)$ \\
\hline & & & & & 0.64 & \\
\hline & Defaulter & $6(54.5 \%)$ & $5(45.5 \%)$ & $0.33(0.09-1.20)$ & 0.21 & $0.36(0.07-1.79)$ \\
\hline & Relapse & $25(71.4 \%)$ & $10(28.6 \%)$ & $0.68(0.28-1.68)$ & 0.88 & $0.92(0.29-2.84)$ \\
\hline & Others & $69(78.4 \%)$ & $19(21.6 \%)$ & 1.00 & & 1.00 \\
\hline \multirow{2}{*}{ Sensory Loss } & Present & $221(72.5 \%)$ & $84(27.5 \%)$ & $2.04(1.41-2.96)$ & 0.036 & $1.72(1.06-2.77)$ \\
\hline & Absent & $117(56.3 \%)$ & $91(43.8 \%)$ & 1.00 & & 1.00 \\
\hline Sign of nerve & Yes & $273(86.7)$ & $42(13.3 \%)$ & $13.30(8.56-20.64)$ & & $13.09(8.07-21.25)$ \\
\hline \multirow[t]{2}{*}{ Damage } & & & & & 0.000 & \\
\hline & No & $65(32.8 \%)$ & $133(67.2 \%)$ & 1.00 & & 1.00 \\
\hline \multirow[t]{2}{*}{ RR } & Present & $120(81.6 \%)$ & $27(18.4 \%)$ & 3.01(1.89-4.81) & 0.038 & $1.85(1.03-3.33)$ \\
\hline & Absent & $218(59.6 \%)$ & $148(40.8 \%)$ & 1.00 & & 1.00 \\
\hline
\end{tabular}


With regard to the risk factors, age is one of the factors found associated with disability. The risk of nerve impairment which leads to disability increases with age; this has also been reported by other studies (13-15). Our study also confirms higher prevalence of disability with increasing age. The risk of development of disability was high in those patients who had symptom for more than 24 months. This is also consistent with the results of previous studies which showed a higher risk of disability in patients who had symptom for 6 to 12 month and more than 24 months (13). Patients who had RR had associated disability; this finding is also consistent with previous studies $(13,16)$.

This study has limitation as it involved only one tertiary level hospital. More severe cases are likely to be seen here which may have overestimated the prevalence of disability.

This study showed that disability is very high among registered leprosy patients. The rate of disability in newly registered leprosy cases was also very high. Grade II disability is much higher than the acceptable percentage (which is below $10 \%)$. This implies that action is needed to improve early case detection and prevention of disability. The risk factors identified in this study, nerve damage and sensory loss, are results of prolonged duration of illness and delay in diagnosis. Therefore, it is important to urgently evaluate the case detection mechanism and the diagnosis system. It is also important to assess the diagnostic suspicion of the first line health workers in the periphery, and the public awareness on the symptoms and signs of leprosy in order to seek health care.

\section{ACKNOWLEDGEMENTS}

We would like to thank Addis Continental Institute of Public Health, University of Gonder, and ALERT Hospital for their support in the research work. Our special acknowledgement goes to ALERT Hospital staff especially to those in the record room and treatment unit.

\section{AUTHORS' CONTRIBUTIONS}

TS was the principal investigator responsible for designing and conduction the study. Further, she was involved in analyzing the data and writing up the manuscript. MD participated in designing the study, data analysis and writeup of the manuscript. YM was involved in designing, data analysis and writeup of the manuscript. All authors read and approved the final manuscript.

\section{REFERENCES}

1. Bhat RM, Prakash C. Leprosy: an overview of pathophysiology. perspectives on infectious diseases, 2012;2012:181089. Epub 2012/09/19.

2. Shetty VP, Dosh RP. Detection and Classification of Leprosy: Future Needs and Strategies. Indian J Lepr, 2008;80 : 139-147.

3. Spierings E, De Boer $\mathrm{T}$, Zulianello $\mathrm{L}$, Ottenhoff TH. Novel mechanisms in the immunopathogenesis of leprosy nerve damage: the role of Schwann cells, T cells and Mycobacterium leprae. Immunology and cell biology, 2000;78(4):349-55. Epub 2000/08/18.

4. van Brakel WH, Sihombing B, Djarir H, Beise $\mathrm{K}$, Kusumawardhani L, Yulihane $\mathrm{R}$, et al. Disability in people affected by leprosy: the role of impairment, activity, social participation, stigma and discrimination. Global health action, 2012;5. Epub 2012/07/25. doi: 10.3402/gha.v5i0.18394.

5. Global leprosy update, 2013; reducing disease burden. Releve epidemiologique hebdomadaire/Section d'hygiene du Secretariat de la Societe des Nations Weekly epidemiological record / Health Section of the Secretariat of the League of Nations. 2014;89(36):389-400. Epub 2014/09/10.

6. Kar BR, and Job CK, Visible Deformity in Childhood Leprosy A 10-Year Study, journal of leprosy and Other Mycobacterial Diseases,dec, 2005;73(4):243-8.

7. Sarkar J, Dasgupta A, Dutt D. Disability among new leprosy patients, an issue of concern: An institution based study in an endemic district for leprosy in the state of West Bengal, India. Indian $J$ Dermatol Venereol Leprol, 2012;78:328-34.

8. Smith WCS, Nicholls PG, Das L, Barkataki P, Suneetha S, Predicting Neuropathy and Reactions in Leprosy at Diagnosis and Before Incident Event Results from the INFIR Cohort Study. PLoS Negl Trop Dis .2009,3(8):e500.

9. WHO EXECUTIVE BOARD, Leprosy (Hansen disease),WHO EB128/16128th Session Provisional agenda item 4.13 , 2010. 
10. Brandsma JW, Van Brakel WH. WHO disability grading: operational definitions. Leprosy review, 2003;74(4):366-73. Epub 2004/01/31.

11. Raposo MT, Caminha AV, Heukelbach J, Sanchez-Gonzalez MA, de Medeiros JL, Nemes MI. Assessment of physical impairments in leprosy patients: a comparison between the world health organization (who) disability grade and the Eye-Hand-Foot score. Revista do Instituto de Medicina Tropical de Sao Paulo, 2011;53(2):77-81. Epub 2011/05/04.

12. Department of health and families Center for disease control, guidelines for control of leprosy in the northern territory, 2010 third edition-www.nt.gov.au/health.

13. Moschioni C, Antunes CMdF, Grossi MAF, Lambertucci JR. Risk factors for physical disability at diagnosis of 19,283 new cases of leprosy. Revista da Sociedade Brasileira de Medicina Tropical, 2010;43:19-22.
14. Moet FJ, Pahan D, Schuring RP, Oskam L, Richardus JH. Physical distance, genetic relationship, age, and leprosy classification are independent risk factors for leprosy in contacts of patients with leprosy. The Journal of infectious diseases, 2006;193(3):346-53. Epub 2006/01/03.

15. Ranque B, Nguyen VT, Vu HT, Nguyen TH, Nguyen NB, Pham XK, et al. Age is an important risk factor for onset and sequelae of reversal reactions in Vietnamese patients with leprosy. Clinical infectious diseases: an official publication of the Infectious Diseases Society of America. 2007;44(1):33-40. Epub 2006/12/05.

16. Motta AC, Pereira KJ, Tarquinio DC, Vieira MB, Miyake K, Foss NT. Leprosy reactions: coinfections as a possible risk factor. Clinics (Sao Paulo). 2012;67(10):1145-8. Epub 2012/10/17. 